\section{Medicine use among adolescents: the 11-year follow-up of the 1993 Pelotas (Brazil) birth cohort study}

\author{
Utilização de medicamentos por adolescentes: \\ a visita de 11 anos da coorte de nascimentos de \\ Pelotas, Rio Grande do Sul, Brasil, 1993
}

1 Centro de Ciências da Saúde, Universidade do Vale do Rio dos Sinos, São Leopoldo, Brasil.

2 Universidade da Região da Campanha, Centro de Ciências da Saúde, Bagé, Brasil.

3 Programa de Pós-graduação em Epidemiologia

Universidade Federal de Pelotas, Pelotas, Brasil. 4 Programa de Pós-graduação em Educação Física Universidade Federal de Pelotas, Pelotas, Brasil. 5 Faculdade de Nutrição, Universidade Federal de Pelotas, Pelotas, Brasil.

Correspondence A. D. Bertoldi

Centro de Ciências da Saúde Universidade do Vale do Rio dos Sinos.

Av. Unisinos 950, São Leopoldo, RS 93022-000, Brasil. andreabertoldi@terra.com.br

\begin{abstract}
The aim of this study was to investigate medicine use and associated factors among adolescents. This was a prospective cohort study including 4,452 adolescents born in Pelotas, Rio Grande do Sul State, Brazil, in 1993. Information on medicine use in the 15 days prior to the interviews was collected from the mothers. Overall prevalence of medicine use was $30.9 \%$, and $64.7 \%$ of the medicines had been prescribed by a physician. The most frequently used pharmacological groups were medicines for the nervous (35.9\%) and respiratory systems (25.7\%). Medicine use was directly associated with socioeconomic status, maternal schooling, complications during pregnancy or delivery, and neonatal problems resulting in the need for intensive care. Underweight and obese adolescents were more likely to use medicines as compared to those with normal body mass index. A direct association was observed between maternal use of hypnotic drugs and sedatives and adolescent medicine use. It is essential to implement educational policies aimed at promoting rational use of medicines by adolescents.
\end{abstract}

Pharmaceutical Preparations; Adolescent; Cohort Studies
Andréa D. Bertoldi 1

Noemia U. L. Tavares 2

Pedro C. Hallal 3,4

Cora Luiza Araújo 3,5

Ana M. B. Menezes 3

\section{Introduction}

Medicines are an important therapeutic tool and an essential health resource, accounting for a significant part of the improvement in the population's quality of life and life expectancy. However, their irrational use poses direct and indirect risks to the population, while increasing the overall health costs and raising a highly relevant public health problem 1 .

Medicine use is reaching high levels in both developed and developing countries. In Brazil, although the population has problems in accessing medicines 2 , their use is high in all age brackets 3,4 . Various factors contribute to this situation, including: difficulty in access to health services, lack of adequate pharmacovigilance, unrestricted sale of medicines in pharmacies and drugstores, and current society's steadfast belief in the power of medicines 5,6,7.

Since adolescence is a phase of new sensations and experiences, it is considered a risk period for the use of substances, including medicines, and the possible harm related to such use 8 . According to the literature, certain risk behaviors like smoking or drinking in adolescence are associated with the use of some therapeutic classes of medicines like those used for headache, digestive diseases, and anxiety 9 .

In 1999-2001, the Brazilian National System of Toxicological and Pharmacological Information (SINITOX) recorded 218,692 cases of human 
poisoning, resulting in 1,233 deaths. Adolescents (10-19 years of age) accounted for $15.5 \%$ of the poisonings and $10.8 \%$ of the deaths. Medicines were the main cause of poisoning in the 15-19year age bracket and the second cause in the $10-14$-year bracket in Brazil as a whole (33\% and $25.7 \%$ ); in the South, the proportions were $32.4 \%$ and $22.8 \%$ in the two respective age brackets 8 .

In Brazil, epidemiological surveys on the use of licit and illicit psychoactive substances have identified medicines (e.g., anabolic steroids and amphetamines), next to alcohol and tobacco, as one of the most frequent substance abuse groups in adolescents 10,11.

The virtual lack of specific research in Brazil on medicine use by adolescents makes it essential to study the pattern of medicine use and associated factors in this age group ${ }^{12}$. The current study thus aims to describe medicine use by adolescents belonging to a birth cohort. We selected variables from the perinatal study and interviews with mothers and adolescents that could be considered possible individual determinants of medicine use. We also described the most widely used pharmacological groups, reasons for use, and origin of the prescription.

\section{Methods}

All the hospital births in the city of Pelotas, Rio Grande do Sul State, Brazil, in 1993 were recorded. The mothers answered a questionnaire, and the newborns were weighed and measured. Subsamples were visited at 1, 3, and 6 months and 1, 4, 6, and 9 years of age. In 2004-2005, all the cohort participants were searched for a new follow-up, the methodological details of which are described elsewhere 13 .

Data were collected by interviewing the mother and adolescent. Mothers were asked about medicine use by the adolescent in the 15 days prior to the interview. For reported medicine use, mothers were asked for the name of the medicine, the reason for its use, and whether it had been prescribed by a physician. The medicines were later classified in pharmacological groups based on the Anatomical Therapeutic Chemical (ATC) classification system 14 . The ATC has five levels of classification, ranging from the organ systems in which the drug acts (level 1) to the drug itself (level 5). The reasons for use were coded according to the International Classification of Diseases, 10th revision (ICD-10) 15.

From the perinatal study, we analyzed the variable pertaining to health problems in the newborn, when this led to ICU admission during the birth hospitalization. The independent vari- ables analyzed from the mother's questionnaire were: family's socioeconomic status, mother's schooling, complications in the pregnancy or delivery that led to disease in the child lasting into adolescence, and medicine use (sedatives and/or hypnotics) by the mother.

The independent variables analyzed from the adolescent's questionnaire were: sedentary lifestyle (defined as less than 300 minutes per week of physical activity in commuting or leisure, according to the current recommendation for adolescents), self-reported skin color (classified as white or black/brown), gender, and nutritional status (underweight, normal, overweight, and obese according to the classification of the World Health Organization 16).

Based on interviews with 4,452 adolescents, we estimated the prevalence of medicine use with a $1.5 \%$ margin of error and $95 \%$ confidence level. To study factors associated with medicine use, the sample allowed detecting as significant prevalence ratios of 1.15 or greater for exposures affecting $3 \%$ to $50 \%$ of the study population, with $80 \%$ power and $95 \%$ confidence level.

The descriptive, crude, and multivariate analyses used Stata 9.0 (Stata Corp., College Station, USA). The descriptive analysis included absolute numbers and percentages for all the study variables. In the crude analysis, the prevalence of medicine use was calculated for the categories of independent variables. Significance was evaluated with the chi-square (heterogeneity or linear trend) test. In the multivariate analysis, Poisson regression was used 17, with the order of entry of variables according to the hierarchical causality model 18 determined $a$ priori. The first level of the model used here included demographic variables (gender and skin color), socioeconomic variables (family's socioeconomic status and mother's schooling), and early health variables (complications in the pregnancy or delivery that led to a disease in the child lasting until adolescence and neonatal health problems that led to ICU admission during the birth hospitalization). The second level used current variables (nutritional status, sedentary lifestyle, and use of hypnotics and/ or sedatives by the mother). Significance was set at $5 \%$, and all the tests were two-tailed.

The study was approved by the Research Ethics Committee at the School of Medicine of the Federal University in Pelotas. The parents or guardians signed a free and informed consent form, authorizing the children's participation in the study. 


\section{Results}

According to the mothers, $30.9 \%$ of the adolescents (95\% confidence interval - 95\%CI: 29.5 ; 32.3) had used some medicine in the 15 days prior to the interview. The most frequently used pharmacological group according to ATC level 1 was medicines acting on the nervous system (35.9\%), following those acting on the respiratory system $(25.7 \%)$, systemic anti-infectives (10.3\%), those acting on the alimentary tract and metabolism (6.9\%), and anti-parasitics (5.3\%). The other groups were used by the adolescents in fewer than $5 \%$ of cases (Table 1 ).

Table 1 also describes the most frequent pharmacological subgroups (ATC level 2) among the five most frequently used groups (ATC level 1), as well as the proportions of medical prescriptions. Use of a total of 1,856 medicines was re- ported, the majority of which $(64.7 \%)$ by medical prescription. Among the medicines acting on the nervous system, the most frequent were analgesics, anticonvulsants, and psychoanaleptics. Medical prescription of the medicines occurred in $34.7 \%$ of the analgesics and $100 \%$ of the other cases. In the group of medicines acting on the respiratory system, expectorants were the most frequently used, and only bronchodilators and nasal corticosteroids were used exclusively by medical prescription. Systemic anti-infectives were used without a medical prescription in $6.4 \%$ of the cases. Among the medicines acting on the alimentary tract and metabolism, the most frequent were vitamins and mineral supplements and anti-emetics. Anthelmintics were the most widely used antiparasitics, $77.8 \%$ of which by medical prescription. Among the other groups not shown in the table, natural products and

Table 1

Distribution of the most frequently used pharmacological groups, classified according to the Anatomical Therapeutic Chemical (ATC; levels 1 and 2) classification system 14. 1993 Pelotas (Brazil) birth cohort study, 2004-2005 follow-up $(n=1,856)$.

\begin{tabular}{|c|c|c|c|}
\hline Medicines & $\mathbf{n}$ & $\%$ & $\begin{array}{c}\text { By medical } \\
\text { prescription (\%) }\end{array}$ \\
\hline N: Nervous system & 666 & 35.9 & \\
\hline N02 Analgesics & 545 & 29.4 & 34.7 \\
\hline N03 Anticonvulsants & 54 & 2.9 & 100.0 \\
\hline N06 Psychoanaleptics & 47 & 2.5 & 100.0 \\
\hline Others & 20 & 1.1 & \\
\hline R: Respiratory system & 477 & 25.7 & \\
\hline R05 Expectorants & 103 & 5.6 & 28.0 \\
\hline R03 Bronchodilators & 83 & 4.5 & 100.0 \\
\hline R06 Antihistamines & 72 & 3.9 & 87.1 \\
\hline R01 Nasal decongestants & 61 & 3.3 & 86.4 \\
\hline R05 Cough medicines & 51 & 2.8 & 17.7 \\
\hline R05 Mucolytics & 35 & 1.9 & 60.6 \\
\hline R01 Nasal corticosteroid drops & 24 & 1.3 & 100.0 \\
\hline Others & 48 & 2.4 & \\
\hline \multicolumn{4}{|l|}{ J: Systemic anti-infectives } \\
\hline J01 Systemic antibacterials & 191 & 10.3 & 93.6 \\
\hline A: Alimentary tract/Metabolism & 128 & 6.9 & \\
\hline A11 Vitamins & 52 & 2.8 & 58.8 \\
\hline A04 Anti-emetics & 19 & 1.0 & 79.0 \\
\hline Others & 57 & 3.1 & \\
\hline P: Antiparasitics & 99 & 5.3 & \\
\hline P02 Anti-helmintics & 91 & 4.9 & 77.8 \\
\hline Others & 08 & 0.4 & \\
\hline Others & 295 & 15.9 & \\
\hline Total & 1,856 & 100.0 & 64.7 \\
\hline
\end{tabular}


medicines acting on the musculoskeletal system were used in some $4 \%$ of cases. Among the latter, anti-inflammatory drugs were the most frequent, accounting for $4.3 \%$ of all the medicines reported, mostly by medical prescription ( $82.3 \%)$.

Table 2 lists the reasons for medicine use reported by the adolescents' mothers, according to ICD-10. The main reasons were diseases of the respiratory system $(29 \%)$, with flu the most frequent in this group, followed by general signs and symptoms (26.5\%) like headache, fever, and pain. Headache stood out as the single most frequent reason for use of medicines $(14.6 \%)$. Signs and symptoms related to the respiratory and circulatory systems were reported in $11.5 \%$ of cases, with cough as the most frequently reported reason in this group. Infectious and parasitic diseases and mental and behavioral disorders accounted respectively for $6.8 \%$ and $4.2 \%$ of the reasons for medicine use.

Table 3 shows the prevalence of medicine use in relation to demographic, socioeconomic, health, and behavioral variables in the study sample $(\mathrm{N}=4,452)$. Prevalence of medicine use was distributed equally by gender and was slight- ly higher among white as compared to black and brown adolescents. Medicine use was higher in the more privileged household asset index quintiles and when mothers had more schooling. Medicine use was $40-50 \%$ higher in adolescents whose mothers reported some complication in the pregnancy or delivery that caused a disease lasting into adolescence or some health problem at the time of birth that led to ICU admis sion for the newborn. There was no difference in medicine use according to level of physical activity (sedentary lifestyle). As for nutritional status, underweight and obese adolescents showed the highest medicine use. There was a direct relationship between use of hypnotics and sedatives by the mother in the 30 days prior to the interview and medicine use by the adolescent.

Table 3 also shows the crude and adjusted analysis of medicine use according to the study's exposure categories. After adjusted analysis, no difference was observed in medicine use according to gender, skin color, or sedentary lifestyle, while white adolescents used $16 \%$ more medicines than the others in the crude analysis. Medicine use was directly associated with economic

Table 2

Distribution of most frequently reported reasons for use of medicines, classified according to the International Classification of Diseases, 10th revision (ICD-10) 15. 1993 Pelotas (Brazil) birth cohort study, 2004-2005 follow-up, $(n=1,856)$.

\begin{tabular}{|c|c|c|}
\hline Reason for use & n & $\%$ \\
\hline \multicolumn{3}{|l|}{ Diseases of the respiratory tract $(n=533)$} \\
\hline Flu & 174 & 9.4 \\
\hline Acute amigdalitis & 71 & 3.9 \\
\hline Acute sinusitis & 58 & 3.1 \\
\hline Asthma & 50 & 2.7 \\
\hline Unspecific bronchitis & 48 & 2.0 \\
\hline \multicolumn{3}{|l|}{ General signs and symptoms $(n=490)$} \\
\hline Headache & 270 & 14.6 \\
\hline Fever & 134 & 7.3 \\
\hline Pain & 37 & 2.0 \\
\hline Seizures & 34 & 1.8 \\
\hline \multicolumn{3}{|l|}{ Signs and symptoms of the respiratory and circulatory systems $(n=213)$} \\
\hline Cough & 130 & 7.0 \\
\hline Other signs and symptoms & 57 & 3.1 \\
\hline Sore throat and chest pain & 20 & 1.1 \\
\hline \multicolumn{3}{|l|}{ Infectious and parasitic diseases $(n=126)$} \\
\hline Helminth infections & 87 & 4.7 \\
\hline \multicolumn{3}{|l|}{ Mental and behavioral disorders $(n=77)$} \\
\hline Behavioral and emotional disorders of childhood and adolescence & 38 & 2.1 \\
\hline Others & 638 & 35.2 \\
\hline Total & 1,846 & 100.0 \\
\hline
\end{tabular}


Table 3

Prevalence of medicine use and crude and adjusted analyses with the target exposure categories. 1993 Pelotas (Brazil) birth cohort study, 2004-2005 follow-up, $(\mathrm{N}=4,452)$.

\begin{tabular}{|c|c|c|c|c|c|}
\hline \multirow[t]{3}{*}{ Variables } & \multicolumn{5}{|c|}{ Use of medicines in previous 15 days } \\
\hline & \multirow[t]{2}{*}{ Use (\%) } & \multicolumn{2}{|c|}{ Crude analysis } & \multicolumn{2}{|c|}{ Adjusted analysis } \\
\hline & & PR $(95 \% \mathrm{Cl})$ & p-value & PR $(95 \% \mathrm{Cl})$ & $\mathrm{p}$-value \\
\hline Gender * & & & 0.326 ** & & $0.096 * \star$ \\
\hline Male & 30.2 & 1.00 & & 1.00 & \\
\hline Female & 31.6 & $1.05(0.96 ; 1.14)$ & & $1.08(0.99 ; 1.18)$ & \\
\hline Skin color (self-reported) * & & & 0.004 ** & & 0.120 ** \\
\hline White & 32.1 & $1.16(1.05 ; 1.29)$ & & $1.07(0.96 ; 1.20)$ & \\
\hline Black/Brown & 27.6 & 1.00 & & 1.00 & \\
\hline Household assets index (quintiles) * & & & $<0.001 * \star \star$ & & $0.008 * \star \star$ \\
\hline 1 & 25.6 & 1.00 & & 1.00 & \\
\hline 2 & 28.7 & $1.12(0.96 ; 1.31)$ & & $1.11(0.95 ; 1.29)$ & \\
\hline 3 & 34.2 & $1.34(1.15 ; 1.55)$ & & $1.29(1.11 ; 1.50)$ & \\
\hline 4 & 30.8 & $1.20(1.03 ; 1.40)$ & & $1.14(0.97 ; 1.34)$ & \\
\hline 5 & 36.5 & $1.42(1.23 ; 1.64)$ & & $1.28(1.08 ; 1.53)$ & \\
\hline Mother's schooling (years) * & & & $<0.001 * * *$ & & $0.016 * \star \star$ \\
\hline $0-4$ & 26.5 & 1.00 & & 1.00 & \\
\hline $5-8$ & 30.5 & $1.15(1.02 ; 1.30)$ & & $1.10(0.97 ; 1.24)$ & \\
\hline $9-11$ & 33.2 & $1.25(1.10 ; 1.43)$ & & $1.13(0.98 ; 1.31)$ & \\
\hline$\geq 12$ & 39.4 & $1.49(1.28 ; 1.74)$ & & $1.28(1.06 ; 1.55)$ & \\
\hline $\begin{array}{l}\text { Complication in pregnancy or childbirth leading to } \\
\text { disease until adolescence * }\end{array}$ & & & $<0.001$ ** & & $<0.001 * *$ \\
\hline No & 29.8 & 1.00 & & 1.00 & \\
\hline Yes & 46.0 & $1.54(1.36 ; 1.76)$ & & $1.49(1.29 ; 1.71)$ & \\
\hline $\begin{array}{l}\text { Health problem leading to ICU admission during birth } \\
\text { hospitalization }\end{array}$ & & & 0.002 ** & & $0.005 * \star$ \\
\hline No & 30.6 & 1.00 & & 1.00 & \\
\hline Yes & 43.5 & $1.42(1.14 ; 1.77)$ & & $1.37(1.10 ; 1.71)$ & \\
\hline Sedentary lifestyle ( $<300$ minutes/week) \# & & & $0.060 * \star$ & & $0.306 * \star$ \\
\hline No & 29.0 & 1.00 & & 1.00 & \\
\hline Yes & 31.7 & $1.09(1.00 ; 1.20)$ & & $1.05(0.96 ; 1.16)$ & \\
\hline Nutritional status \#.\#\# & & & $<0.001$ ** & & $<0.001 * \star$ \\
\hline Underweight & 38.7 & $1.33(1.15 ; 1.55)$ & & $1.34(1.15 ; 1.57)$ & \\
\hline Normal & 29.0 & 1.00 & & 1.00 & \\
\hline Overweight & 32.2 & $1.11(0.97 ; 1.28)$ & & $1.09(0.94 ; 1.25)$ & \\
\hline Obese & 36.0 & $1.24(1.09 ; 1.41)$ & & $1.20(1.05 ; 1.37)$ & \\
\hline Use of hypnotics and sedatives by mother in previous & & & $<0.001 * * *$ & & $<0.001 * \star \star$ \\
\hline 30 days \# & & & & & \\
\hline Neither & 29.4 & 1.00 & & 1.00 & \\
\hline One or the other & 38.6 & $1.31(1.13 ; 1.52)$ & & $1.24(1.06 ; 1.45)$ & \\
\hline Both & 41.1 & $1.40(1.21 ; 1.61)$ & & $1.40(1.21 ; 1.62)$ & \\
\hline
\end{tabular}

95\% Cl: 95\% confidence interval; PR: prevalence ratio.

* Level 1 variables;

** Chi-square test for heterogeneity of proportions;

*** Chi-square test for linear trend;

\# Level 2 variables (all the variables are controlled for all the others at the same level and the level above, with p from 5\% to 20\%);

\#\# According to World Health Organization (WHO) classification 16. 
status and maternal schooling (28\% higher in the groups with more household assets and higher maternal schooling). When the mother reported some complication during the pregnancy or delivery causing a disease that lasted into adolescence, the risk of medicine use in adolescence was $49 \%$ greater. Medicine use was also $37 \%$ higher for adolescents who had experienced some neonatal health problem leading to ICU admission during the birth hospitalization. Compared to normal nutritional status, underweight adolescents used $34 \%$ more medicines and obese adolescents used 20\% more. Maternal use of hypnotics and sedatives in the 30 days prior to the interview was directly associated with medicine use by the adolescent. When the mother used only one of these two types of medicines, the adolescent used $24 \%$ more medicines than children of mothers that did not use either type, and when the mother used both types, the adolescent used $40 \%$ more medicines.

\section{Discussion}

Previous studies have shown that adolescents, as compared to newborns, children, and older persons, show lower prevalence of medicine use $3,19,20$, especially in the preadolescent age bracket (10-14 years) 21 .

Although medicine use is lower in adolescence than in other age brackets, studies have shown high self-medication rates in this age group 4,22,23. In addition, nonmedical use of psychoactive substances by adolescents is similar to that observed in adults 10 .

The prevalence of medicine use observed in the current study was lower than in a nationwide Brazilian study on medicine use by secondary students (49.5\%), using a seven-day recall period ${ }^{12}$. Pereira et al. ${ }^{4}$ evaluated self-medication in children and adolescents (0-18 years) in two Brazilian cities and also found a higher prevalence of medicine use (56.6\%) than in the current study, using a 15-day recall period.

A study in Spain 24 found $25.4 \%$ medicine use in children under 15 years of age in the previous two days. Another study showed that $60 \%$ of the 0 -16-year age group had used at least one medicine that year 21 . The variations in age brackets, which included early childhood, in which medicine use is high 19 , and the variations in recall periods may explain the observed differences.

Some methodological factors may have limited the current study's results. A 15-day recall period was used to analyze medicine use, possibly leading to a certain degree of error. Mother's reporting on medicine use by the adolescent may have been another limiting factor, although the literature shows high agreement for parents' reporting of medicine use in adolescents, especially for headache, digestive problems, and asthma 25 .

Drugs acting on the nervous system were the most widely used group, and analgesics were the most frequent among these, accounting for one-third of all medicine use. Silva \& Giugliani 12 found a similar result, with analgesics representing $24.7 \%$ of use. Our prevalence was higher than in schoolchildren and adolescents in the Netherlands $(10 \%) 21$. In studies on self-medication among adolescents, analgesics were also the most widely used medicines, reaching up to $41.7 \% 4,23$. In the current study, about one-third of analgesics had been prescribed by a physician, and although analgesics are relatively safe medicines in this age bracket, chronic use and abuse should be avoided 26. The other types of drugs acting on the nervous system (anticonvulsants and antidepressants) were used entirely by medical prescription, which is important, considering that anxiolytics are reported as the most widely consumed drug of abuse in this age bracket 10 .

Among the reported systemic anti-infectives, the majority were used by medical prescription, which is important since their irrational use contributes to the appearance of adverse reactions and the development of bacterial resistance 26 . Pereira et al. 4 have reported that these medicines account for $8 \%$ of all the medicines used by children and adolescents in self-medication, usually in partially consumed packets and frequently with the date expired. The current study showed a lower rate, i.e., only $1.8 \%$ of all the medicines used without a medical prescription were systemic anti-infectives.

According to this study, the reasons for use of medicines were consistent with other studies, with headache as the most frequent 23,25 and heavy use of analgesics. Respiratory tract diseases and signs like flu and cough have been reported as frequent in this age bracket 4,22 , and the group of medicines acting on the respiratory system was the second most widely used among adolescents in the current study. However, diseases of the digestive tract, reported by some authors as the second most frequent reason for medicine use in this age bracket 23,25 , were not very frequent in the current sample (3.3\%).

In the current study, no difference was found in medicine use according to gender, unlike other studies that report heavier medicine use by girls $12,22,23$. Schirm et al. 21 found heavier medicine use by boys in childhood and an increase in use by girls in adolescence, extending into adult$\operatorname{hood} 3$. 
Medicine use was directly associated with the adolescent's economic status. In adults, studies have shown $30 \%$ to $40 \%$ greater use of medicines 3,5 among individuals with incomes greater than three times the minimum wage and more than eight years of schooling 5 as compared to poorer and less educated individuals. Although some studies have shown that prevalence of self-medication in children and adolescents is independent of socioeconomic status 4,12,19, it is important to highlight the easy access to some classes of medicines in Brazil, like analgesics, sold freely without a medical prescription and potentially leading to abusive use of these medicines. In this study, $34.7 \%$ of all analgesics were taken without a prescription.

Maternal schooling was also directly associated with medicine use by adolescents. Silva \& Giugliani 12 found an inverse association between maternal schooling and medicine use by secondary school students.

Health problems in adolescents related to complications in pregnancy or delivery or neonatal health problems leading to ICU admission during the birth hospitalization were strongly associated with medicine use in adolescence. No similar data were found in the literature, but future analyses using the data from this same cohort may help show how closely these variables are related to medicine use in other stages of life, like adulthood.

Adolescents at the extremes of nutritional status (underweight and obese) used more medicines than their peers. This association is wor- risome, because other studies have identified heavy use of medicines related to the quest for a "perfect body" in this age group, with heavier use of amphetamines in girls and anabolic steroids in boys (even though the current study did not identify this phenomenon) 10,11 .

The use of hypnotics and sedatives by the mother was strongly associated with medicine use by adolescents, consistent with the literature, showing a strong family influence on medicine use by adolescents. This association can be explained by direct stimulus or example, whereby parents portray medicine use as routine ${ }^{12}$. Mothers are also the leading source of information on medicine for children and are responsible for most off-prescription administration of medicines to adolescents 4,22 .

This study's results reinforce the family's important role, particularly the mother's, on medicine use among adolescents. Although the prevalence of medicine use in adolescence is lower than in other age groups, it is during this life phase that use begins to increase until adulthood, thus highlighting the extreme importance of educational measures to raise awareness on the risks of improper use such as self-medication and use of medicines for non-therapeutic purposes. Therefore, it is crucial to promote rational use of medicines beginning in school age, understanding medicines as a resource for health rather than consumption, to be used adequately as an essential tool for the promotion and recovery of the population's health. 


\section{Resumo}

O objetivo deste estudo foi investigar o uso de medicamentos e fatores associados em adolescentes. Tratase de estudo de coorte prospectivo, incluindo 4.452 adolescentes nascidos em Pelotas, Rio Grande do Sul, Brasil, em 1993. As informações sobre o uso de medicamentos pelo adolescente nos 15 dias anteriores à entrevista foram fornecidas pelas mães. A prevalência global de uso de medicamentos foi de 30,9\%, sendo que destes, 64,7\% foram indicados por médicos. Os grupos farmacológicos mais utilizados foram os medicamentos que atuam nos sistemas nervoso $(35,9 \%)$ e respiratório (25,7\%). O uso de medicamentos esteve diretamente associado ao nível econômico, escolaridade da mãe, intercorrência na gravidez ou parto que gerou doença até a adolescência, problema de saúde no momento do nascimento que levou o recém-nascido à UTI, magreza e obesidade. Foi observada uma relação direta entre uso de medicamentos hipnóticos e sedativos pela mãe e uso de medicamentos pelo adolescente. É fundamental que medidas educativas sejam voltadas à promoção do uso racional de medicamentos nesta faixa etária.

Medicamentos; Adolescente; Estudos de Coortes

\section{Contributors}

A. D. Bertoldi and N. U. L. Tavares led the writing of the article and the crude data analysis and approved the final version submitted for publication. P. C. Hallal, C. L. Araújo, and A. M. B. Menezes coordinate the 1993 Pelotas birth cohort and approved the final version of the article.

\section{Acknowledgments}

The cohort study is supported by the Wellcome Trust. The initial phases of the cohort were funded by the European Union and the Brazilian National Program for Centers of Excellence (PRONEX), National Research Council (CNPq), and Ministry of Health.

\section{References}

1. Marin N, Luiza VL, Osorio-de-Castro CG, Machado-dos-Santos S. Assistência farmacêutica para gerentes municipais. Rio de Janeiro: Organização Pan-Americana da Saúde/Organização Mundial da Saúde; 2003.

2. Carvalho MF, Pascom AR, Souza-Júnior PR, Damacena GN, Szwarcwald CL. Utilization of medicines by the Brazilian population, 2003. Cad Saúde Pública 2005; 21 Suppl 1:S100-8.

3. Bertoldi AD, Barros AJ, Hallal PC, Lima RC. Utilização de medicamentos em adultos: prevalência e determinantes individuais. Rev Saúde Pública 2004; 38:228-38.

4. Pereira FS, Bucaretchi F, Stephan C, Cordeiro R. Self-medication in children and adolescents. J Pediatr (Rio J.) 2007; 83:453-8.

5. Arrais PSD, Brito LL, Barreto ML, Coelho HLL. Prevalência e fatores determinantes do consumo de medicamentos no município de Fortaleza, Ceará, Brasil. Cad Saúde Pública 2005; 21:1737-46.
6. Lefèvre F. A oferta e a procura de saúde através do medicamento: proposta de um campo de pesquisa. Rev Saúde Pública 1987; 21:64-7.

7. Lima JC, Azoury EB, Bastos LHCN, Coutinho MM, Pereira NN, Ferreira SCC. Desigualdades no acesso e utilização de serviços de saúde no Brasil. Saúde Debate 2002; 26:62-70.

8. Bochner R. Perfil das intoxicações em adolescentes no Brasil no período de 1999 a 2001. Cad Saúde Pública 2006; 22:587-95.

9. Andersen A, Holstein BE, Hansen EH. Is medicine use in adolescence risk behavior? Cross-sectional survey of school-aged children from 11 to 15 . J Adolesc Health 2006; 39:362-6.

10. Dal Pizzol TS, Branco MM, Carvalho RMA, Pasqualotti A, Maciel EN, Migott AMB. Uso não-médico de medicamentos psicoativos entre escolares do ensino fundamental e médio no Sul do Brasil. Cad Saúde Pública 2006; 22:109-15. 
11. Tavares BF, Béria JU, Lima MS. Prevalência do uso de drogas e desempenho escolar entre adolescentes. Rev Saúde Pública 2001; 35:150-8.

12. Silva CH, Giugliani ER. Consumo de medicamentos em adolescentes escolares: uma preocupação. J Pediatr (Rio J.) 2004; 80:326-32.

13. Araújo CL, Menezes AMB, Vieira MFA, Neutzling MB, Gonçalves H, Anselmi L, et al. The 11-year follow-up of the 1993 Pelotas (Brazil) birth cohort study: methods. Cad Saúde Pública 2010; 26: 1875-86.

14. World Health Organization. Anatomical Therapeutic Chemical (ATC) Classification Index with defined daily doses (DDDs). Oslo: WHO Collaborating Centre for Drug Statistics Methodology; 2000.

15. World Health Organization. International statistical classification of diseases and related health problems, $10^{\text {th }}$ revision. Geneva: World Health Organization; 1992.

16. World Health Organization. Physical status: the use and interpretation of anthropometry. Report of a WHO Expert Committee. Geneva: World Health Organization; 1995. (Technical Report Series, 854).

17. Barros AJ, Hirakata VN. Alternatives for logistic regression in cross-sectional studies: an empirical comparison of models that directly estimate the prevalence ratio. BMC Med Res Methodol 2003; $3: 21$.

18. Victora CG, Huttly SR, Fuchs SC, Olinto MT. The role of conceptual frameworks in epidemiological crude analysis: a hierarchical approach. Int J Epidemiol 1997; 26:224-7.
19. Béria JU, Victora CG, Barros FC, Teixeira AB, Lom bardi C. Epidemiologia do consumo de medicamentos em crianças de centro urbano da região sul do Brasil. Rev Saúde Pública 1993; 27:95-104.

20. Loyola Filho AI, Uchoa E, Lima-Costa MF. Estudo epidemiológico de base populacional sobre uso de medicamentos entre idosos na Região Metropolitana de Belo Horizonte, Minas Gerais, Brasil. Cad Saúde Pública 2006; 22:2657-67.

21. Schirm E, van den Berg P, Gebben H, Sauer P, De Jong-van den Berg L. Drug use of children in the community assessed through pharmacy dispensing data. Br J Clin Pharmacol 2000; 50:473-8.

22. Abahussain E, Matowe LK, Nicholls PJ. Self-reported medication use among adolescents in Kuwait. Med Princ Pract 2005; 14:161-4.

23. Holstein BE, Holme Hansen E, Due P, Birna Almarsdottir A. Self-reported medicine use among 11-to-15-year-old girls and boys in Denmark 19881998. Scand J Public Health 2003; 31:334-41.

24. Rajmil L, Ruiz C, Segú JL, Fernández E, Segura A. Factores asociados al consumo de medicamentos en la población infantil. Med Clin (Barc) 2000; 114:214-6.

25. Andersen A, Krolner R, Holstein BE, Due P, Hansen EH. Medicine use among 11- and 13-year-olds: agreement between parents' reports and children's self-reports. Ann Pharmacother 2007; 41:581-6.

26. Bricks LF. Uso judicioso de medicamentos em crianças. J Pediatr (Rio J.) 2003; 79 Suppl 1:S107-14.

Submitted on $31 /$ Jan/2009

Final version resubmitted on 11/Aug/2009

Approved on 22/Sep/2009 